\title{
Injury incidence and characteristics in South African school first team rugby: A case study
}

\author{
J C Tee, ${ }^{1}$ PhD; F Lebatie, ${ }^{2}$ BSc (Phys); K Till, ${ }^{1}$ PhD; B Jones, ${ }^{1}$ \\ $\mathrm{PhD}$ \\ 1. School of Sport, Leeds Beckett University, Leeds, United Kingdom \\ 2. Floyd Lebatie Physiotherapy, Jeppe High School for Boys, Kensington \\ South Africa
}

Corresponding author: J C Tee (j.c.tee@leedsbeckett.ac.uk)

Background: Despite its apparent popularity, participation in the sport of rugby union is accompanied by a significant risk of injury. Concerned parties have recently questioned whether this risk is acceptable within school populations. This is difficult to assess within the South African schools' population as no recent longitudinal injury studies exist.

Objectives: To determine the training habits, rugby-related exposure and injury risk within a population of South African high school first team rugby players.

Methods: Training and match exposure in both school and provincial competition were examined and the resultant injuries were longitudinally observed for the duration of a South African high school rugby season.

Results: Match $(79,95 \% \mathrm{CI} 52-105$ injuries/1 $000 \mathrm{~h})$ and training (7, 95\%CI 3-11 injuries $/ 1000 \mathrm{~h})$ injury incidences were demonstrated to be greater than previously reported incidences in similar populations in England and Ireland. Weeks where players were exposed to both school and provincial competition (34, 95\%CI 19-49 injuries /1 $000 \mathrm{~h}$ ) had significantly $(\mathrm{p}<0.05)$ greater injury incidences than during school competition alone (19,95\%CI 12-26 injuries /1 $000 \mathrm{~h})$.

Conclusion: The injury risk demonstrated was greater than expected and represents reasons for concern. Possible reasons for the high injury incidence recorded may be the frequency of games played within the season, and the overlap of school and provincial competitions. It should be noted that these results were taken from one school over one season and might not be representative of the incidence of school rugby injuries overall. However, this research demonstrates the need for a multischool longitudinal study within South African schools rugby to determine the overall risk.

Keywords: rugby union, youth, injury risk, provincial, multicompetition

\section{S Afr J Sports Med 2017;29:1-7. DOI: 10.17159/2078-516X/2017/v29i0a1532}

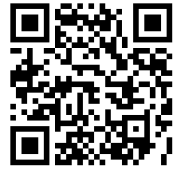

Rugby union is a collision sport, with more than 2.8 million players in 120 countries worldwide. [1] In recent years, the game has been exposed to increasing levels of scrutiny regarding the safety of participation. ${ }^{[2-3]}$ Meta-analysis has revealed that the mean injury incidence is $81,95 \% \mathrm{CI} 63-105$ injuries /1 $000 \mathrm{~h}$ in matches and 3, 95\%CI 2-4 injuries /1000 h in training for professional players. ${ }^{[4]}$

Recently public interest groups have questioned whether the overall risk of injury, particularly at school level, is acceptable. They have even gone as far as to suggest that tackling should be banned from school rugby. [2] In their response, World Rugby have called for longitudinal injury surveillance research to be undertaken at school level in order to accurately quantify the risks to school rugby players. ${ }^{[3]}$ Some research on this topic exists, ${ }^{[5-10]}$ but because of the variation in the methods of reporting and injury definitions applied, it is difficult to make comparisons across studies. ${ }^{[3]}$

In the largest and most comprehensive study of this subject to date, Palmer-Green et al. reported a match injury incidence of $35,95 \%$ CI 29-41 injuries / 1000 player h during matches with a mean injury severity of 30 days (95\%CI 25-35) for English school level players. ${ }^{7]}$ These authors also found that in training, the injury incidence was 1.7 injuries / $1000 \mathrm{~h}$ and mean severity was 27 days (95\%CI 9-45). ${ }^{[8]}$ The Rugby Injury Surveillance in Ulster Schools project reported a match injury incidence of 29 per 1000 player hours, but did not provide training data. ${ }^{[5]}$

In South Africa, landmark studies performed in 1982 and 1987 estimated the "missed subsequent match" injury incidence to be 7, 95\%CI 0-21 injuries /1000 player h. ${ }^{[9-10]}$ These studies were conducted before the advent of professionalism in rugby union, and the game has since changed significantly. Subsequent to these studies, the focus of youth rugby injury research has been on the national provincial weeks tournaments. ${ }^{[11-13]}$ At these tournaments, it was reported that the match injury incidence was $29,95 \% \mathrm{CI} 18-39$ injuries $/ 1000 \mathrm{~h}$ at U18 level. ${ }^{[1]}$ This research reports the injury profile of a single provincial competition week, but falls short of the type of longitudinal injury surveillance methodology required to make effective risk evaluations regarding the safety of the game at this level. ${ }^{[3]}$

Therefore the aim of this present study was to provide a preliminary longitudinal injury case study of a single U19 South African school rugby team. It describes the training habits and exposure levels typical of the South African school rugby system, and provides insights into the injury risks for players at this level.

\section{Methods}

\section{Participants}

The team investigated is from a well-established rugby playing school that was ranked in the Top 20 rugby schools in South Africa at the end of the 2016 rugby season across a range of ranking systems. Players were aged between 16 and 18 years on the $1^{\text {st }}$ of January 2016, and were members of the school's first XV rugby squad. The player cohort comprised 23 players (14 forwards and 9 backs) with physical characteristics as presented in Table 1.

\section{Procedures}

Data regarding all injuries and training exposure throughout the 2016 school rugby season (including the preseason) from 25 January to 6 August 2016 were collected by the team's Strength and Conditioning coach. The team's physiotherapist confirmed 
all injury diagnoses. These were later retrospectively analysed to determine injury incidence. Ethical approval for the study was obtained from the Leeds Beckett University Ethics Committee.

Injuries were classified according to the "time-loss" definition provided by the 2007 International Rugby Board (IRB) consensus statement ${ }^{[14]}$. Injury severity was calculated as the total number of days elapsed from the day of injury until a player returned to full training or match participation. [14] Injuries were recorded on an MS Excel spreadsheet with a coding system which included the injury date, body site, type of injury, whether the injury occurred during a match or training session, whether the injury occurred as the result of a contact/collision event, and the date that the player returned to full participation following injury.

Match and training exposure times were individually recorded for each player during each onfield participation. When squad players were not selected for the school's first $\mathrm{XV}$ matches, their exposure in the second $\mathrm{XV}$ matches was recorded. These involvements were then summed to provide the overall team match and training exposure time. Gym sessions were not included in the analysis. Over the course of the study period, players were involved in a multistage provincial trials process, and depending on progression through the trials, players were exposed to additional rugby involvement through provincial training and games. Table 2 provides a summary of how the training week is affected when players have to attend both school and provincial training sessions. Exposure and injuries due to provincial involvement were treated separately to school team involvement. Where it was
Table 1. Physical characteristics of school player cohort $(n=23)$

\begin{tabular}{lcccc}
\hline & $\begin{array}{c}\text { Whole group } \\
(\mathbf{n = 2 3 )}\end{array}$ & $\begin{array}{c}\text { Backs } \\
(\mathbf{n = 9 )}\end{array}$ & $\begin{array}{c}\text { Forwards } \\
(\mathbf{n = 1 4 )}\end{array}$ & $\begin{array}{c}\text { Likelihood and } \\
\text { magnitude of difference }\end{array}$ \\
\hline Stature (cm) & $178 \pm 6$ & $176 \pm 7$ & $180 \pm 6$ & $\begin{array}{c}\text { Likely, medium } \\
\text { Body Mass (kg) }\end{array}$ \\
\hline Vertical Jump (cm) & $58.4 \pm 13.3$ & $78.7 \pm 6.8$ & $95.7 \pm 12.4$ & Very likely, very large \\
1RM bench press (kg) & $94 \pm 15$ & $54 \pm 6$ & $47 \pm 7$ & Very likely, large \\
5RM squat (kg) & $132 \pm 23$ & $120 \pm 22$ & $140 \pm 21$ & Unclear, medium \\
40m sprint (s) & $5.4 \pm 0.3$ & $5.2 \pm 0.3$ & $5.5 \pm 0.3$ & Likely, large \\
Yo-Yo IRT1 (m) & $933 \pm 354$ & $1217 \pm 287$ & $711 \pm 216$ & Likely, large \\
\hline
\end{tabular}

1RM, one repetition maximum; 5RM, five repetition maximum; Yo-Yo IRT1, Yo-Yo intermittent recovery test one. Data presented as mean $\pm \mathrm{SD}$.

Likelihood represents the chance that the true value of the difference between groups is substantially positive or negative according to the following scale $-<1 \%$, almost certainly not; $1 \%$ to $5 \%$, very unlikely; $5 \%$ to $25 \%$, unlikely; $25 \%$ to $75 \%$, possible; $75 \%$ to $95 \%$, likely; $95 \%$ to $99 \%$, very likely; $>99 \%$, almost certain. Magnitude of difference represents Cohen's effect size statistic. ESs of 0.2, 0.6, 1.2 and 2.0 were considered small, medium, large and very large respectively.

Table 2. In-season weekly training schedule for a South African high school rugby first team during weeks representing the school only or school and province combined

\begin{tabular}{|c|c|c|c|c|}
\hline \multicolumn{3}{|c|}{ School-only } & \multicolumn{2}{|c|}{ School and province combined } \\
\hline Day & Activity & $\begin{array}{l}\text { Time } \\
\text { (mins) }\end{array}$ & Activity & $\begin{array}{l}\text { Time } \\
\text { (mins) }\end{array}$ \\
\hline \multirow[t]{3}{*}{ Monday } & Gym & 45 & Provincial training & 100 \\
\hline & $\begin{array}{l}\text { Aerobic training and small } \\
\text { sided games }\end{array}$ & 60 & $\begin{array}{l}\text { (combination of attack, } \\
\text { defence and unit skills) }\end{array}$ & \\
\hline & Total & 105 & Total & 100 \\
\hline \multirow[t]{5}{*}{ Tuesday } & Warm up and skills & 20 & Warm up & 20 \\
\hline & Defence & 30 & Provincial match & 60 \\
\hline & Breakdown & 30 & & \\
\hline & $\begin{array}{l}\text { Units skills } \\
\text { (backs/forwards) }\end{array}$ & 30 & & \\
\hline & Total & 110 & Total & 80 \\
\hline \multirow[t]{2}{*}{ Wednesday } & $\begin{array}{l}\text { Rest } \\
\text { (Occasional additional } \\
\text { lineout session for } \\
\text { forwards) }\end{array}$ & (30) & Rest & \\
\hline & Total & (30) & Total & 0 \\
\hline \multirow[t]{6}{*}{ Thursday } & Gym & 30 & Gym & 30 \\
\hline & Speed and Agility & 20 & Speed and Agility & 20 \\
\hline & Attack skills and structure & 45 & Breakdown/defence & 30 \\
\hline & Unit skills & 30 & Attack structure & 30 \\
\hline & (backs/forwards) & & Unit skills (backs/forwards) & 30 \\
\hline & Total & 125 & Total & 140 \\
\hline \multirow[t]{2}{*}{ Friday } & Captains run & 30 & Captains run & 30 \\
\hline & Total & 30 & Total & 30 \\
\hline \multirow[t]{3}{*}{ Saturday } & Warm up & 30 & Warm up & 30 \\
\hline & Match & 70 & Match & 70 \\
\hline & Total & 100 & Total & 100 \\
\hline \multirow[t]{2}{*}{ Sunday } & Rest / recovery & & Rest / recovery & \\
\hline & Total & 0 & Total & 0 \\
\hline $\begin{array}{l}\text { Total for } \\
\text { week }\end{array}$ & & 470 & & 450 \\
\hline
\end{tabular}

not possible for the investigator to directly observe these provincial training sessions and matches, exposure time was collected via a player report. Figure 1 provides the comparative amount of time spent per week on school and provincial rugby throughout the season. In order to determine the effect of playing for both school and provincial teams simultaneously, injury incidence was compared for weeks where players represented school-only, province-only and school and province combined. 


\section{Statistical analyses}

Injury incidence was calculated for matches, training and overall rugby exposure as the number of injuries per 1000 player hours for both school and provincial rugby exposure. Independent injury incidences were further calculated for periods of the season where players participated in school-only (17 weeks), province-only (five weeks) and school and province combined (six weeks) rugby. 95\% confidence intervals (95\%CI) were calculated according to the methods of Knowles et al.[16] Injury incidence between different groups (e.g. backs vs. forwards) or studies was compared by calculating incidence rate ratios (IRR) and magnitude-based inferences (MBI) using a custom designed spreadsheet

(www.sportsci.org). ${ }^{[15]} \mathrm{MBI}$ represents the likelihood that the true value is substantially positive or negative according to the following scale $-<1 \%$, most unlikely; $1 \%$ to $5 \%$, very unlikely; $5 \%$ to $25 \%$, unlikely; $25 \%$ to $75 \%$, possibly; $75 \%$ to $95 \%$, likely; $95 \%$ to $99 \%$, very likely; >99\%, most likely. Injury severity was calculated as the mean \pm SD number of days absence from training and match play. However, given the practical nature of this study, the size of effect was assessed calculating Cohen's effect size (ES) statistic. ${ }^{[15]}$ ESs of $0.2,0.6,1.2$ and 2.0 were considered small, medium, large and very large respectively. ${ }^{[15]}$ Injury burden was calculated as the total number of days absent from training and match play.

\section{Results}

\section{Exposure}

In total, players were exposed to 2088 hours of rugby activity during the school season (training 1668 hours, matches 420 hours). This equated to a total of 78 scheduled training sessions and 20 interschool matches over the season (training to match ratio approx. $4: 1)$. exposures

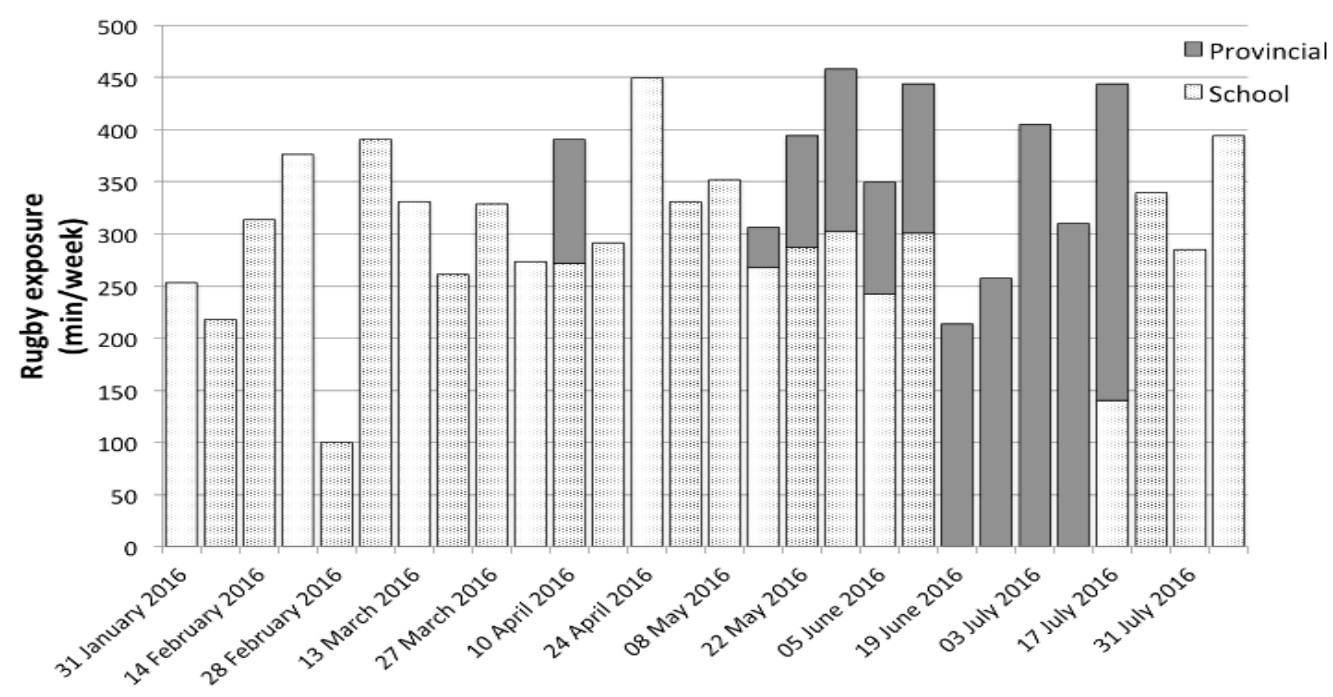

Fig. 1. Average weekly exposure of South African high school rugby players to school and provincial rugby.

Table 3. Comparison of injury incidence during matches and training for backs and forwards for all

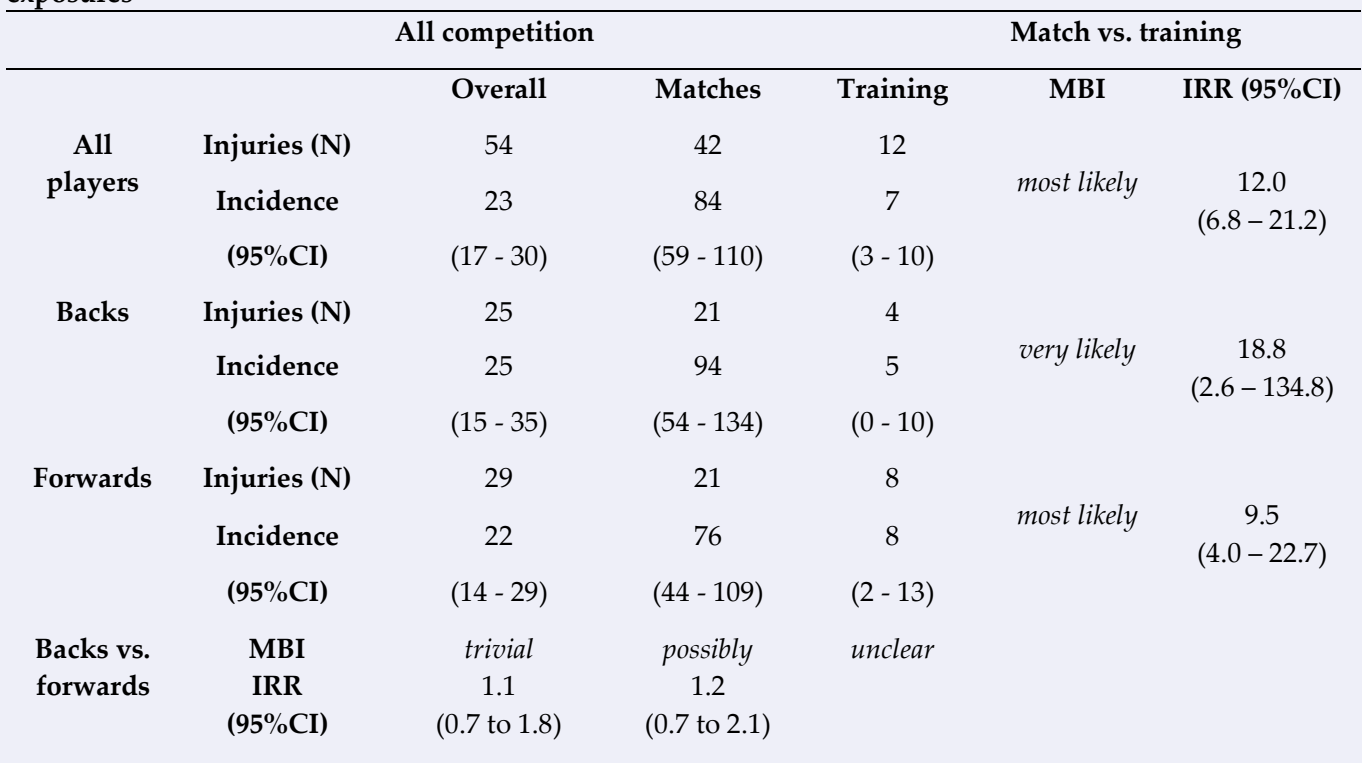

Injuries indicates the total number of injuries that occurred. Incidence is the number of injuries per 1000 hours of exposure time $(95 \% \mathrm{CI})$. MBI represents the likelihood that the true value is substantially positive or negative according to the following scale - <1\%, most unlikely; $1 \%$ to $5 \%$, very unlikely; $5 \%$ to $25 \%$, unlikely; $25 \%$ to $75 \%$, possibly; $75 \%$ to $95 \%$, likelu: $95 \%$ to $99 \%$. veru likelu: $>99 \%$. most likelu. IRR renresents the incidence rate ration with $9.5 \%$ confidence intervals.

Participation in provincial rugby led to an additional 221 hours of rugby exposure (training 142 hours, matches 79 hours). Consequently, on average, each school player was exposed to an additional $4 \pm 5$ (range 0 to 14 ) training sessions and $4 \pm 3$ (range 1 to 8 ) matches (training to match ratio approx. 1:1).

\section{Incidence of injury}

\section{Match vs. training}

Overall, a total of 54 time-loss injuries were sustained (42 match, 12 training). The overall injury incidence was 23 injuries per 1000 player exposure hours (95\%CI 17-30). The match injury incidence (84 injuries per 1000 match hours; 95\%CI, 59110) was most likely greater that the training injury incidence (7 injuries per 1000 training hours; 95\%CI 3-10) (IRR 12.0 95\%CI 6.8-22.1) (Table 3). Injury incidence for school and provincial 
Table 4. Comparison of injury incidence during matches and training for backs and forwards for school and provincial exposures

\begin{tabular}{|c|c|c|c|c|c|c|c|c|c|c|}
\hline & & \multicolumn{3}{|c|}{ School competition } & \multicolumn{2}{|c|}{ Match vs. training } & \multicolumn{3}{|c|}{ Provincial competition } & \multirow{2}{*}{ 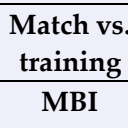 } \\
\hline & & Overall & Matches & Training & MBI & IRR $(95 \% C I)$ & Overall & Matches & Training & \\
\hline \multirow{3}{*}{$\begin{array}{c}\text { All } \\
\text { players }\end{array}$} & Injuries (N) & 45 & 33 & 12 & & 11.3 & 9 & 9 & 0 & unclear \\
\hline & Incidence & 22 & 79 & 7 & $\begin{array}{l}\text { most } \\
\text { likely }\end{array}$ & $(6.1-21.0)$ & 41 & 114 & 0 & \\
\hline & $(95 \% \mathrm{CI})$ & $(15-28)$ & $(52-105)$ & $(3-11)$ & & & $(14-68)$ & $(40-188)$ & 0 & \\
\hline \multirow[t]{3}{*}{ Backs } & Injuries (N) & 22 & 18 & 4 & & 16.5 & 3 & 3 & 0 & unclear \\
\hline & Incidence & 26 & 99 & 6 & $\begin{array}{c}\text { very } \\
\text { likely }\end{array}$ & $(2.1-128.3)$ & 23 & 70 & 0 & \\
\hline & $(95 \% \mathrm{CI})$ & $(15-37)$ & $(54-145)$ & $(0-12)$ & & & $(-3-50)$ & $(-9-149)$ & 0 & \\
\hline \multirow[t]{3}{*}{ Forwards } & Injuries (N) & 23 & 15 & 8 & & 7.9 & 6 & 6 & 0 & unclear \\
\hline & Incidence & 18 & 63 & 8 & $\begin{array}{l}\text { most } \\
\text { likely }\end{array}$ & $(3.7-16.6)$ & 64 & 167 & 0 & \\
\hline & $(95 \% \mathrm{CI})$ & $(11-26)$ & $(31-95)$ & $(2-8)$ & & & $(13-115)$ & $(33-300)$ & 0 & \\
\hline \multirow{2}{*}{$\begin{array}{l}\text { Backs vs. } \\
\text { forwards }\end{array}$} & MBI & possibly & possibly & unclear & & & unclear & unclear & unclear & \\
\hline & $\begin{array}{c}\text { IRR } \\
(95 \% \mathrm{CI})\end{array}$ & $\begin{array}{c}1.4 \\
\text { (0.9 to } 2.4)\end{array}$ & $\begin{array}{c}1.6 \\
\text { (0.8 to } 2.9)\end{array}$ & & & & & & & \\
\hline
\end{tabular}

MBI, magnitude based inference; IRR, incidence injuries ratio

Injuries indicates the total number of injuries that occurred. Incidence is the number of injuries per 1000 hours of exposure time (95\%CI). MBI represents the likelihood that the true value is substantially positive or negative according to the following scale - $<1 \%$, most unlikely; $1 \%$ to $5 \%$, very unlikely; $5 \%$ to $25 \%$, unlikely; $25 \%$ to $75 \%$, possibly; $75 \%$ to $95 \%$, likely; $95 \%$ to $99 \%$, very likely; $>99 \%$, most likely. IRR represents the incidence rate ration with $95 \%$ confidence intervals.

Table 5. Comparison of injury severity (days) during matches and training for backs and forwards for all exposures

\begin{tabular}{|c|c|c|c|c|c|c|}
\hline & & \multicolumn{3}{|c|}{ All competition } & \multicolumn{2}{|c|}{ Match vs. training } \\
\hline & & Overall & Matches & Training & MBI & $\begin{array}{l}\text { Effect } \\
\text { Size }\end{array}$ \\
\hline $\begin{array}{c}\text { All } \\
\text { players }\end{array}$ & & $15 \pm 36$ & $18 \pm 40$ & $3 \pm 2$ & likely & $\begin{array}{l}\text { small } \\
(0.42)\end{array}$ \\
\hline Backs & & $5 \pm 4$ & $5 \pm 4$ & $3 \pm 1$ & $\begin{array}{l}\text { most } \\
\text { likely }\end{array}$ & trivial \\
\hline Forwards & & $24 \pm 47$ & $32 \pm 54$ & $3 \pm 2$ & likely & $\begin{array}{c}\text { medium } \\
(0.62)\end{array}$ \\
\hline \multirow[t]{2}{*}{$\begin{array}{l}\text { Backs vs. } \\
\text { forwards }\end{array}$} & MBI & likely & $\begin{array}{l}\text { very } \\
\text { likely }\end{array}$ & most likely & & \\
\hline & $\begin{array}{c}\text { Effect } \\
\text { Size }\end{array}$ & $\begin{array}{l}\text { small } \\
(0.55)\end{array}$ & $\begin{array}{c}\text { medium } \\
(0.71)\end{array}$ & trivial & & \\
\hline
\end{tabular}

MBI, magnitude based inference. Data are presented as mean \pm SD.

MBI represents the likelihood that the true value is substantially positive or negative according to the following scale - $<1 \%$, most unlikely; $1 \%$ to $5 \%$, very unlikely; $5 \%$ to $25 \%$, unlikely; $25 \%$ to $75 \%$, possibly; $75 \%$ to $95 \%$, likely; $95 \%$ to $99 \%$, very likely; $>99 \%$, most likely. Effect size is Cohen's effect size (ES) statistic. ESs of 0.2, 0.6, 1.2 and 2.0 were considered small, medium, large and very large respectively

exposures are provided in Table 4.

\section{Backs vs. forwards}

Backs had a possibly greater match injury incidence than forwards in school rugby (backs 99, 95\%CI 54-145 vs. forwards 63, 95\%CI 31-95 injuries /1 $000 \mathrm{~h}$, IRR 1.6, 95\%CI 0.8 - 2.9) (Table 4). When playing provincial rugby forwards had a likely higher match injury incidence than backs (backs 70 , 95\%CI 9-149 vs. forwards 167, 95\% CI 33-300 injuries /1 000 h, IRR 2.4, 95\%CI 0.5 - 10.7).

\section{Provincial vs. school rugby}

Periods of the season when players participated in school-only rugby (17 weeks), province-only rugby (five weeks), and in school and province combined rugby (six weeks) were compared for overall injury incidence. Injury incidence was likely greater in the weeks where players participated in both school and province combined rugby compared with schoolonly participation (school-only 19, 95\%CI 12-26 vs. school and province combined 34, 95\%CI 19-49 injuries /1 000 h, IRR 1.8, $95 \%$ CI 1.1 - 3.0) (Figure 2). The difference between 
Table 6. Comparison of injury severity during matches and training for backs and forwards for school and provincial exposures

\begin{tabular}{|c|c|c|c|c|c|c|c|c|c|c|}
\hline & & \multicolumn{3}{|c|}{ School rugby } & \multicolumn{2}{|c|}{ Match vs. training } & \multicolumn{3}{|c|}{ Provincial rugby } & \multirow{2}{*}{$\begin{array}{c}\text { Match vs. } \\
\text { training }\end{array}$} \\
\hline & & Overall & Matches & Training & MBI & IRR $(95 \% C I)$ & Overall & Matches & Training & \\
\hline $\begin{array}{c}\text { All } \\
\text { players }\end{array}$ & & $13 \pm 30$ & $16 \pm 34$ & $3 \pm 2$ & possibly & $\begin{array}{l}\text { small } \\
(0.45)\end{array}$ & $27 \pm 58$ & $27 \pm 58$ & - & unclear \\
\hline Backs & & $5 \pm 4$ & $5 \pm 5$ & $3 \pm 1$ & $\begin{array}{l}\text { most } \\
\text { likely }\end{array}$ & trivial & $5 \pm 4$ & $5 \pm 4$ & - & unclear \\
\hline Forwards & & $20 \pm 41$ & $29 \pm 48$ & $3 \pm 2$ & likely & $\begin{array}{c}\text { medium } \\
(0.66)\end{array}$ & $38 \pm 70$ & $38 \pm 70$ & - & unclear \\
\hline \multirow{2}{*}{$\begin{array}{l}\text { Backs vs. } \\
\text { Forwards }\end{array}$} & MBI & likely & likely & most likely & & & unclear & unclear & - & \\
\hline & $\begin{array}{l}\text { Effect } \\
\text { Size }\end{array}$ & $\begin{array}{l}\text { small } \\
(0.51)\end{array}$ & $\begin{array}{c}\text { medium } \\
(0.74)\end{array}$ & trivial & & & $\begin{array}{l}\text { small } \\
(0.56)\end{array}$ & $\begin{array}{l}\text { small } \\
(0.56)\end{array}$ & - & \\
\hline
\end{tabular}

MBI, magnitude based inference. Data are presented as mean \pm SD.

MBI represents the likelihood that the true value is substantially positive or negative according to the following scale - $<1 \%$, most unlikely; $1 \%$ to $5 \%$, very unlikely; $5 \%$ to $25 \%$, unlikely; $25 \%$ to $75 \%$, possibly; $75 \%$ to $95 \%$, likely; $95 \%$ to $99 \%$, very likely; $>99 \%$, most likely. Effect size is Cohen's effect size (ES) statistic. ESs of $0.2,0.6,1.2$ and 2.0 were considered small, medium, large and very large respectively

Table 7. Burden of injury in a South African high school rugby first team as a function of injury site and type

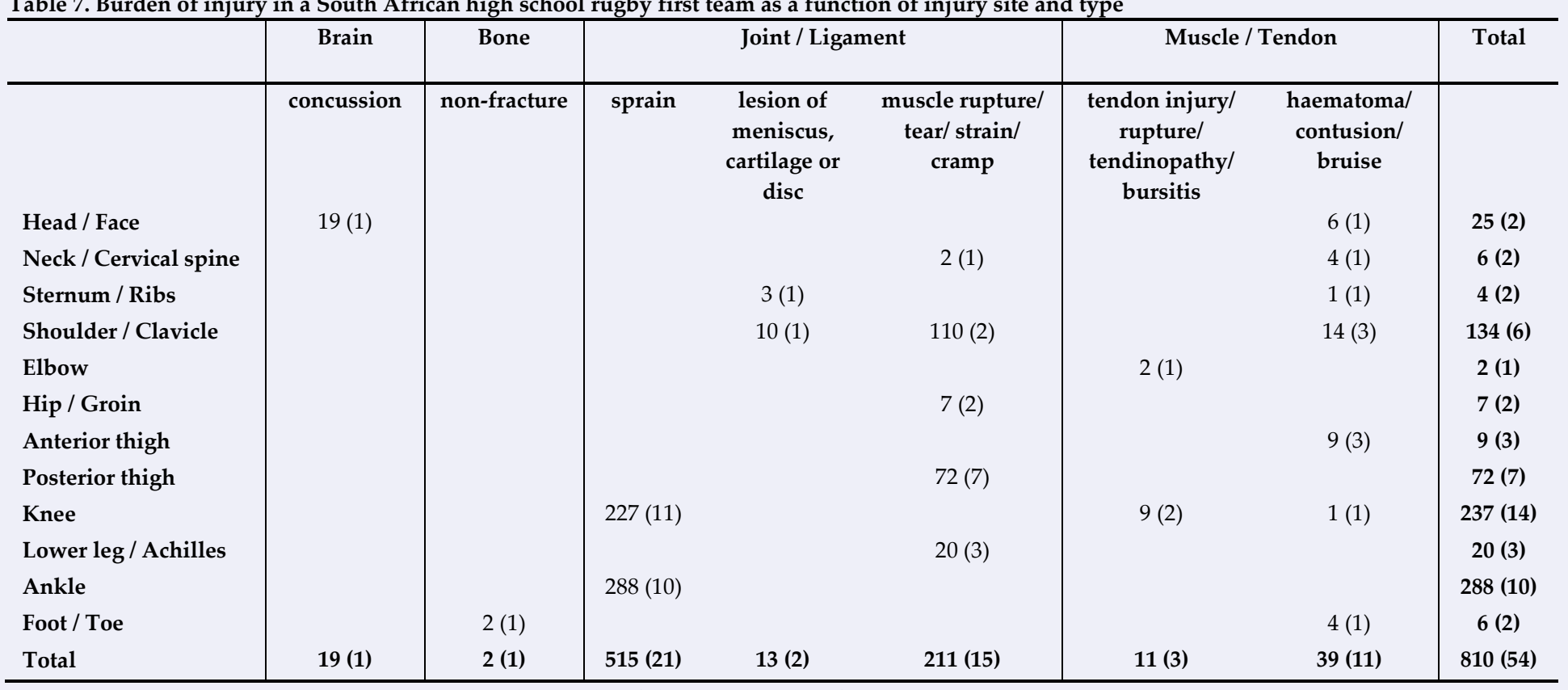

Data are presented as injury burden, the total number of injury days followed by (number of injuries).

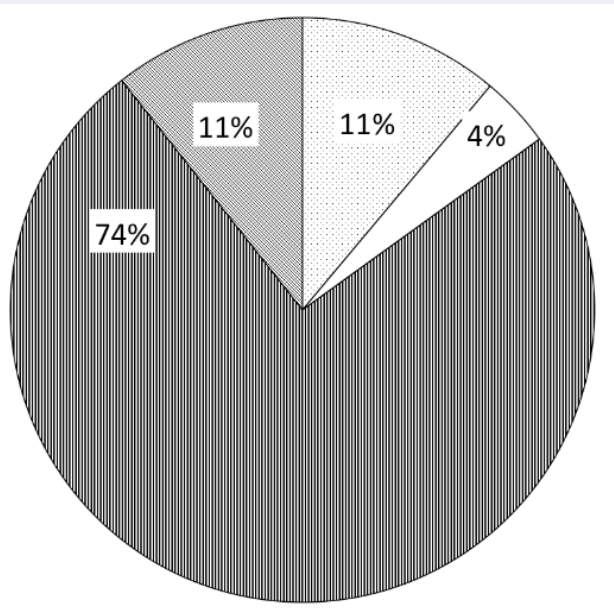

Fig.3. Relative contribution of forwards and backs contact and non-contact injuries to the total team injury burden. provincial-only and school and province combined participation was unclear (provincial participation only 23, 95\%CI -3-49 vs. school and provincial participation 34, 95\%CI 19-49 injuries /1 $000 \mathrm{~h}$ ).
Backs, contact

$\square$ Backs, non-contact

血 Forwards, contact

$\square$ Forwards, non-contact

\section{Injury severity}

The mean severity of all injuries sustained was $15 \pm 36$ days. Data on the severity of injuries for backs and forwards in school and provincial competition are provided in Tables 5 and 6. Overall, there was a likely small difference in the severity of injuries sustained in matches and training (match $18 \pm 40$ vs. training $3 \pm 2$ days, ES = 0.42). A very likely medium difference was present for match injury severity between backs and forwards (backs $5 \pm 4$ vs. forwards $32 \pm 54$, ES $=0.71$ ). The effect of this was that despite sustaining a similar number of overall injuries 
(backs 25 vs. forwards 29), forwards contributed $85 \%$ of the team injury burden (Figure 3).

\section{Nature of injury}

The lower limb was the most commonly injured body area for both backs $(88 \%, 22$ of 25$)$ and forwards $(66 \%, 19$ of 29$)$. Forwards experienced a greater proportion of upper limb injuries relative to backs (backs $0 \%, 0$ of 25 injuries vs. forwards $24 \%, 7$ of 29). Injury incidence and severity were combined to provide the total injury burden by injury site and type (Table 7). The most costly injuries were ligament sprain type injuries to the knee and ankle which when combined accounted for $64 \%$ (515 of 810 days) of the total season injury burden. The majority of injuries $(69 \%, 37$ of 54$)$ occurred as a result of contact events. There was a possibly small difference in the severity of contact versus non-contact injuries (contact $19 \pm 42$ vs. non-contact $7 \pm 13$, ES = 0.34). In total, $692(85 \%)$ training days were lost to contact injury and 122 (15\%) days were lost to non-contact injury.

\section{Discussion}

This is the first study since 1987 to determine the incidence, severity and nature of injury in a South African high school rugby first team using a longitudinal approach to data collection. The key finding of this study was that the injury incidence observed in this player cohort was much larger than would be expected for a group of school-level rugby players. Given that this was a case study, the sample examined was not large enough to provide definitive analysis of the risks that players are exposed to within this category. However, the observations highlighted here illustrate the need for a larger study of this type that incorporates multiple schools.

This study shows that in this cohort, the match injury incidence $(79,95 \% \mathrm{CI} 52-105$ injuries/1 $000 \mathrm{~h})$ is most likely higher than that reported for similar population groups in England (35, 95\%CI 29-41 injuries/1 000 h; IRR 2.3, 95\%CI 1.6-3.1), ${ }^{[7]}$ Ireland (29, 95\%CI 18-40 injuries /1 000 h; IRR 2.7, $95 \%$ CI $1.7-4.3)^{[5]}$ and Scotland $(11,95 \%$ CI 5-18 injuries $/ 1$ 000 h; IRR 7.2, 95\%CI 3.9-13.3). [6] Similarly, the training injury incidence in this study $(7,95 \%$ CI $3-11$ injuries $/ 1$ $000 \mathrm{~h})$ was very likely greater than that reported in England (2, 95\%CI 1-3 injuries /1 000 h; IRR 3.5, 95\%CI 1.7-7.1). ${ }^{[8]}$ Despite the greater injury incidence, the mean severity of match injuries (16 \pm 34 days) in this cohort, was likely lower than in England ( $30 \pm 30$ days) ${ }^{[7]}$ and Ireland ( $24 \pm 20$ days). [5] Similarly, the severity of training injuries was very likely lower in this cohort ( $3 \pm 2$ days) than the England group (27 \pm 55 days). ${ }^{[8]}$ Some of the differences between these studies might be explained by different reporting methods (e.g., whether the researcher was also the primary data collector) in these studies. ${ }^{[3]}$ Despite these inconsistencies, it is still evident that the injury incidence in this study is higher than previously reported. ${ }^{[5-10]}$ This is illustrated by the fact that the incidence reported here is comparable with the incidence in men's senior professional rugby (81 injuries per 1000 training hours; 95\%CI 63-105). ${ }^{[4]}$ These results suggest that the risk of injury in South African school first team rugby is higher than what had previously been determined in other school cohorts. ${ }^{[9-10]}$

When players participated in provincial rugby the match injury incidence was $114,95 \% \mathrm{CI} 40-188$ injuries / $1000 \mathrm{~h}$. This incidence is very likely higher than the English equivalent of Academy rugby (47, 95\%CI 38-45 injuries /1 000 h) [7], and most likely higher than that reported for provincial Youth Week tournaments in South Africa (29, 95\%CI 18-39 injuries $/ 1000 h) .{ }^{[11]}$ This injury incidence was similar to the injury rate reported for international rugby $(123,95 \% \mathrm{CI} 85-177$ injuries /1 000h). ${ }^{[4]}$ This is consistent with observations that injury risk increases with playing level ${ }^{[4]}$, but also indicates that the risk in this cohort is higher than previously reported for similar groups. ${ }^{[7]}$

The nature of injury described in this study was consistent with that previously described across school-, academy- and professional levels within the game. ${ }^{[4-11]}$ The lower limb was the most frequently injured body part, and accounted for $76 \%$ of all injuries. Muscle and tendon injuries were the most frequent injury type, followed closely by joint and ligament injuries. Joint and ligament injuries resulted in the greatest injury burden, and accounted for $64 \%$ of the total time lost. The majority of injuries (69\%) occurred as a result of involvement in a contact event. These results agree with previous research that determined that the tackle is the phase of play most likely to cause injury. [12-13]

It is difficult to determine why the injury incidence in this study was so high compared to other school cohorts. A possible explanation is that due to the heightened profile of school first team rugby in South Africa considerable resources are spent on the recruitment and strength and conditioning of players. Stronger and fitter players are able to exert greater force during tackles and collisions, and may be involved in these phases of play more frequently, thus exposing them to greater risk of injury. [7] This effect is demonstrated by the observation that despite greater body mass and strength (Table 1), forwards accounted for $85 \%$ of the total team injury burden (Figure 3). Injury incidence was higher in provincial matches for forwards, where the majority of players are likely to be better conditioned. The effect may not have been as pronounced for backs, as it is known that backs are exposed to fewer contact events during a match. ${ }^{[17]}$

A second possible explanation is that structure of the South African school rugby season, where players are regularly required to participate in two and sometimes three games per week, is not optimal. These periods lead to reduced opportunity for recovery, causing players to enter subsequent exposure bouts fatigued. [18] These periods reduce the time that could be spent on conditioning activities, thus these players may be less well prepared physically for matches later in the season.

A further contributing factor may be the overlap between school competition and provincial trials competition. It was demonstrated that in the weeks where players participated in both school and province rugby combined, the injury incidence was likely higher than when they participated in 
school rugby only (school only $19,95 \%$ CI 12 to 26 vs. school and provincial 34,95\%CI 19 to 49 injuries per 1000 hours; IRR $1.8,95 \%$ CI $1.1-3.0$ ) (Figure 2). It is important to note that this effect is unlikely to be only due to increased match frequency. In both school-only (Easter Festivals) and provincial-only competition (Craven Week) players were exposed to periods where they played three matches in a week. It seems that the participation for two different teams in different competitions in the same week is an injury risk factor. This might be due to misalignment between schools and provincial training. In these weeks, due to pressure to complete the necessary technical/tactical work required, it is unlikely that adequate attention is paid to conditioning and recovery activities. In addition, playing within two different team environments may contribute to the accumulation of psychological and emotional stress within players. Efforts should be made to reduce congestion in this period of the season, or to reschedule these competitions to prevent overlap. Further research should aim to determine how the stress of two different playing environments (e.g. school and academy, or club and country) may affect player wellbeing and injury risk.

\section{Conclusion}

This is the first longitudinal injury research project to be undertaken in South African school rugby since the advent of professionalism. The injury risk demonstrated was much larger than would be expected for a cohort of schoolboy rugby players, which is reason for concern. Possible reasons for the high injury incidence recorded may be the frequency of games within the season, and the overlap of school and provincial competitions. However, a major limitation of this study is the small sample size used, and the fact that all players represented the same school team. This research demonstrates the need for a larger multischool longitudinal study with South African school rugby to determine the overall risk, and what can be done to mitigate these risks within this population.

Acknowledgements: Thanks to the players and coaching staff of the Jeppe High School for Boys for their cooperation in this research project.

\section{References}

1. World Rugby. 2017. Player Numbers (cited 13 April 2017) [http://www.worldrugby.org/development/player-numbers]

2. Sport Collision Injury Collective. 2016. Open Letter: Preventing injuries in children playing school rugby (cited 11 March [http://www.sportcic.com/resources/Open\%20Letter\%20Spo rtCIC\%20March1st\%202016.pdf]

3. Tucker R, Raftery M, Verhagen E. Injury risk and a tackle ban in youth Rugby Union: reviewing the evidence and searching for targeted, effective interventions. A critical review. Br J Sports Med 2016 Aug;50(15):921-925. PMID: 27324873 DOI:10.1136/bjsports-2016-096322

4. Williams S, Trewartha G, Kemp S, et al. A meta-analysis of injuries in senior men's professional Rugby Union. Sports
Med 2013 Oct;43(10):1043-1055. PMID:23839770 DOI: 10.1007/s40279-013-0078-1

5. Archbold HA, Rankin AT, Webb M, et al. RISUS study: Rugby Injury Surveillance in Ulster Schools. Br J Sports Med 2017 Apr;51(7):600-606. PMID: 26701931 DOI:10.1136/bjsports-2015095491

6. Nicol A, Pollock A, Kirkwood G, et al. Rugby union injuries in Scottish schools. J Public Health (Oxf) 2011 Jun;33(2):256-261. PMID: 20581127 DOI:10.1093/ pubmed/fdq047

7. Palmer-Green DS, Stokes KA, Fuller CW, et al. Match injuries in English youth academy and schools rugby union: an epidemiological study. Am J Sports Med 2013 Apr;41(4):749755. PMID: 23380159 DOI:10.1177/0363546512473818

8. Palmer-Green DS, Stokes KA, Fuller CW, et al. Training activities and injuries in English youth academy and schools rugby union. Am J Sports Med 2015 Feb;43(2):475-481. PMID: 25512663 DOI:10.1177/0363546514560337

9. Roux CE, Goedeke R, Visser GR. The epidemiology of school boy rugby injuries. S Afr Med J 1987 Mar;71(5):307-313

10. Nathan M, Goedeke R, Noakes TD. The incidence and nature of rugby injuries experienced at one school during the 1982 rugby season. S Afr Med J 1983 Jul;64:132-137

11. Brown JC, Verhagen E, Viljoen W, et al. The incidence and severity of injuries at the 2011 South African Rugby Union (SARU) Youth Week tournaments. S Afr J Sports Med 2012;24(2):49-54. DOI: 10.17159/2413-3108/2012/

12. Burger N, Lambert MI, Viljoen W, et al. Tackle technique and tackle-related injuries in high-level South African Rugby Union under-18 players: real-match video analysis. Br J Sports Med 2016 Aug;50(15):932-9388. PMID: 26781294 DOI: 10.1136/bjsports-2015-095295

13. Burger N, Lambert MI, Viljoen W, et al. Tackle-related injury rates and nature of injuries in South African Youth Week tournament rugby union players (under-13 to under-18): an observational cohort study. BMJ Open 2014 Aug;4(8):e005556. PMID: 25116454 DOI:10.1136/bmjopen-2014-005556

14. Fuller CW, Molloy MG, Bagate C, et al. Consensus statement on injury definitions and data collection procedures for studies of injuries in rugby union. Br J Sports Med 2007 May;41(5):328331. PMID: 17452684 DOI:10.1136/bjsm.2006.033282

15. Hopkins WG, Marshall SW, Batterham AM, et al. Progressive statistics for studies in sports medicine and exercise science. Med Sci Sports Exerc 2009 Jan;41(1):3-13. PMID: 19092709 DOI:10.1249/MSS.0b013e31818cb278

16. Knowles SB, Marshall SW, Guskiewicz KM. Issues in estimating risks and rates in sports injury research. J Athl Train 2006 Apr-Jun;41(2):207-215. PMID: 16791309

17. Deutsch MU, Kearney GA, Rehrer NJ. Time - motion analysis of professional rugby union players during match-play. J Sports Sci 2007 Feb 15;25(4):461-472. PMID: 17365533 DOI:10.1080/02640410600631298

18. Roe G, Till K, Darrall-Jones J, et al. Changes in markers of fatigue following a competitive match in elite academy rugby union players. S Afr J Sports Med 2016;28(1):2-5 DOI: 10.17159/2078-516x/2016/v28i1a418 